\title{
Things that go bump in the night: searching for therapeutic targets and underlying mechanisms of night-time calf cramps
}

\author{
Fiona Hawke ${ }^{1,2^{*}}$, Vivienne Chuter ${ }^{1}$, Joshua Burns ${ }^{2,3}$ \\ From Australasian Podiatry Council Conference 2013 \\ Sydney, Australia. 2-5 June 2013
}

\section{Background}

Night-time calf muscle cramps are highly prevalent and painful, yet the underlying mechanism is poorly understood and no treatment has shown consistent efficacy or safety. The aim of this study was to identify factors associated with night-time calf cramping in adults.

\section{Methods}

160 adults were recruited the Greater Newcastle and Central Coast regions of New South Wales, Australia: 80 who experienced night-time calf cramp at least once per week and 80 age- and sex-matched adults who did not. Participants were assessed using reliable tests of foot/ankle and toe strength, range of ankle dorsiflexion, hamstring flexibility, foot alignment, calf circumference, peripheral circulation and sensation. Participants also completed a bespoke survey examining health and lifestyle factors, diet, exercise, lower limb symptoms, sleeping habits and footwear characteristics.

\section{Results}

Presence of night-time calf muscle cramps was significantly correlated with weakness of foot and ankle inversion, eversion, dorsiflexion and plantarflexion; weakness of toe grip; restricted hamstring flexibility; lower limb tingling sensations; muscle twitching, and coldness of legs or feet in bed at night. Conditional logistic regression identified three factors independently associated with night-time calf muscle cramps: muscle twitching (OR 4.6; 95\%CI: 1.6 to $15.5 ; p=0.01$ ), lower limb tingling (OR 4.1; $95 \% \mathrm{CI}: 1.6$ to $10.3 ; p=0.003)$ and foot dorsiflexion

\footnotetext{
* Correspondence: Fiona.Hawke@newcastle.edu.au

'Podiatry Program, The University of Newcastle, Ourimbah, NSW, 2258, Australia

Full list of author information is available at the end of the article
}

weakness (OR 1.02; 95\%CI: 1.01 to $1.03 ; p=0.002$ ), which represented other measures of lower limb weakness in the model.

\section{Conclusion}

Night-time calf muscle cramps were associated with markers of neurological dysfunction and potential musculoskeletal therapeutic targets.

\section{Author details}

'Podiatry Program, The University of Newcastle, Ourimbah, NSW, 2258, Australia. 'Sydney Medical School, The University of Sydney, Westmead, NSW, 2145, Australia. ${ }^{3}$ Arthritis and Musculoskeletal Research Group, Faculty of Health Sciences, The University of Sydney / Institute for Neuroscience and Muscle Research / Paediatric Gait Analysis Service of NSW, Sydney Children's Hospitals Network (Randwick and Westmead), Australia.

Published: 31 May 2013

doi:10.1186/1757-1146-6-S1-O14

Cite this article as: Hawke et al:: Things that go bump in the night: searching for therapeutic targets and underlying mechanisms of nighttime calf cramps. Journal of Foot and Ankle Research 2013 6(Suppl 1):O14.

Submit your next manuscript to BioMed Central and take full advantage of:

- Convenient online submission

- Thorough peer review

- No space constraints or color figure charges

- Immediate publication on acceptance

- Inclusion in PubMed, CAS, Scopus and Google Scholar

- Research which is freely available for redistribution

\section{() Biomed Central}

(C) 2013 Hawke et al; licensee BioMed Central Ltd. This is an Open Access article distributed under the terms of the Creative Commons Attribution License (http://creativecommons.org/licenses/by/2.0), which permits unrestricted use, distribution, and reproduction in any medium, provided the original work is properly cited. 